Int. J. Electrochem. Sci., 15 (2020) 5529 - 5539

Short Communication

\title{
Preparation of Molybdenum doped Nickel Sulfides Supported on Nickel Foam via Two-step Electrodeposition for Oxygen Evolution Reaction
}

\author{
Yi-Wen Dong, Bao-Yu Guo, Qin-Wei Chen, Bin Dong* \\ College of Science, China University of Petroleum (East China), Qingdao 266580, PR China \\ *E-mail: dongbin@upc.edu.cn
}

doi: $10.20964 / 2020.06 .88$

Received: 9 March 2020 / Accepted: 14 April 2020 / Published: 10 May 2020

\begin{abstract}
Nickel sulfides-based electrocatalyst has been believed to be a very promising alternative for noble metal catalysts for efficient oxygen evolution reaction (OER). However, the dispersion and intrinsic activity of active sites for OER still need improvements. In our work, a facile two-step electrodeposition has been used to help the better dispersion of Ni sties and realize the Mo doping for enhanced intrinsic activity of $\mathrm{Ni}_{3} \mathrm{~S}_{2}$ supported on nickel foam (Mo-Ni $3 \mathrm{~S}_{2} / \mathrm{NF}$ ). Firstly, Mo/Ni/NF as precursor has been obtained by through the two-step electrodeposition of $\mathrm{Ni}$ and Mo, respectively. Secondly, the hydrothermal sulfurization of the precursor provides the homogeneous dispersion of Mo$\mathrm{Ni}_{3} \mathrm{~S}_{2}$ nanoparticles on NF. The prepared Mo-Ni3 $\mathrm{S}_{2} / \mathrm{NF}$ for OER only needs a low overpotential of 179 $\mathrm{mV}$ to reach the current density of $50 \mathrm{~mA} \mathrm{~cm}{ }^{-2}$ in alkaline solution. The excellent stability has also been kept for more than $10 \mathrm{~h}$. This result suggest that the method of electrodeposition can be a promising way for constructing transition metal-based sulfides electrocatalysts for OER.
\end{abstract}

Keywords: nickel sulfides; electrodeposition; doping; oxygen evolution reaction

\section{$\underline{\text { FULL TEXT }}$}

(C) 2020 The Authors. Published by ESG (www.electrochemsci.org). This article is an open access article distributed under the terms and conditions of the Creative Commons Attribution license (http://creativecommons.org/licenses/by/4.0/). 